PRACE NAUKOWE UNIWERSYTETU EKONOMICZNEGO WE WROCLAWIU

\title{
Magdalena Grębosz
}

Politechnika Łódzka

e-mail: magdalena.grebosz@p.lodz.pl

\section{BADANIA POSTAW NOSTALGICZNYCH KONSUMENTÓW WOBEC MAREK}

\section{THE RESEARCH ON NOSTALGIC ATTITUDES OF CONSUMERS TOWARDS BRANDS}

DOI: $10.15611 /$ pn.2016.460.10

JEL Clasification: M31

Streszczenie: Nostalgia to pozytywne nastawienie lub korzystna postawa wobec ludzi, miejsc, produktów i marek, które były znane konsumentowi w czasach jego młodości. Wyniki badań prowadzonych w zagranicznych ośrodkach potwierdzają pozytywny wpływ nostalgii na postawy i zachowania konsumentów, zwłaszcza w obszarze komunikacji marketingowej. Celem artykułu jest próba przedstawienia koncepcji nostalgii w marketingu oraz ocena postaw nostalgicznych konsumentów wobec marek z wykorzystaniem istniejących technik pomiarowych. W artykule wykorzystano informacje pochodzące ze źródeł wtórnych i pierwotnych. Głównym celem studiów literaturowych było dokonanie krytycznej analizy koncepcji marki nostalgicznej. W artykule przedstawiono także wyniki własnych badań pilotażowych dotyczących postaw nostalgicznych młodych konsumentów z Francji i Polski. Analiza wyników badań potwierdza pozytywną ocenę marek nostalgicznych przez młodych konsumentów, zwłaszcza w przypadku marek pokoleniowych.

Słowa kluczowe: nostalgia, postawy konsumentów, marka.

Summary: Nostalgia is a positive or favourable attitude toward people, places, products and brands that were known by a consumer in his/her youth. The results of research conducted abroad confirm the positive effect of nostalgia on the attitudes and behaviours of consumers, especially in the area of marketing communication. The aim of this article is to present the concept of nostalgia in marketing and the assessment of the nostalgic attitudes of consumers towards brands, using existing measurement. In the article information from primary and secondary sources is used. The main purpose of literature studies was to make a critical analysis of the concept of nostalgic brand. The article presents also the results of own pilot studies on the nostalgic attitudes of young consumers in France and Poland. The analysis of the research results confirmed positive nostalgic attitudes of young consumers towards brands, especially generational brands.

Keywords: nostalgia, consumers attitudes, brand. 
Najważniejsze jest, by gdzieś istniało to, czym się żyto: i zwyczaje, i święta rodzinne.

I dom peten wspomnień.

Najważniejsze jest, by żyć dla powrotu.

A. de Saint-Exupéry

\section{Wstęp}

Decydującym uzasadnieniem podjęcia tematu postaw nostalgicznych konsumentów wobec marek są luki istniejące zarówno w obszarze opracowań teoretycznych, jak i badań empirycznych. W polskiej literaturze przedmiotu brak jest kompleksowego ujęcia problematyki nostalgii w zarządzaniu marką, które dałoby całościowy obraz koncepcji. W literaturze polskiej dotychczas ukazało się zaledwie kilka artykułów podejmujących tę problematykę i są to głównie publikacje o charakterze popularno-naukowym. Należy także podkreślić fakt, iż problematyka nostalgii w zarządzaniu marketingowym jest często postrzegana w Polsce jedynie przez pryzmat powrotu do kultury realizmu socjalistycznego, co jest podejściem bardzo ograniczonym. Wyniki badań pilotażowych dowodzą bowiem, że marki nostalgiczne to dla polskich konsumentów marki z długoletnią tradycją, związane przede wszystkim z doświadczeniami z życia osobistego. W opracowaniach podejmujących zarówno tematykę marketingu, jak i zarządzania marką koncepcja nostalgii jest pomijana lub traktowana $\mathrm{w}$ sposób sygnalny. Głównym źródłem informacji pozostaje zatem światowa literatura przedmiotu, która koncentruje się tylko na wybranych aspektach zarządzania marketingowego. Warto podkreślić, że światowe badania dotyczą przede wszystkim wpływu nostalgii na zachowania konsumentów w kontekście popytu na produkty powiązane z przeszłością.

Celem artykułu jest próba przedstawienia koncepcji nostalgii w marketingu oraz ocena postaw nostalgicznych konsumentów wobec marek z wykorzystaniem istniejących technik pomiarowych. W artykule przedstawiono także przykładowe wyniki własnych badań pilotażowych dotyczących postaw nostalgicznych młodych konsumentów z Francji i Polski.

Projekt badawczy był częściowo finansowany z programu francuskich stypendiów rządowych oraz ze środków Narodowego Centrum Nauki (projekt OPUS 9, nr 2015/17/B/HS4/00945, „Nostalgia w zarządzaniu marką”) na lata 2016-2019.

\section{Koncepcja nostalgii w naukach społecznych}

Koncepcję nostalgii w naukach społecznych rozwinął Davis [1979], definiując ją jako sposób na utrzymanie własnej tożsamości wobec głównych przemian w cyklu życia. Zjawisko nostalgii jest obecnie przedmiotem badań w takich obszarach, jak: socjologia (Stauth i Turner 1988; Bartmanski 2011), psychologia (Ross 1991; 
Castelnuovo-Tedesco 1998), polityka i historia (Lowenthala 1985; Riabczuk 2009; Lee 2011; Fletcher 2012), antropologia (DaSilva i Faught 1982; Stewart 1988; Graburn 1995), architektura (Peleggi 2005), turystyka (Vesey i Dimanche 2003; Ritchie i Adair 2004; Russell 2008), semiotyka (Kessous i Roux 2008) czy sztuka (Huppatz 2009; Leaver i Schmidt 2010).

Do marketingu pojęcie nostalgii zostało wprowadzone przez Holbrooka i Schindlera [1991] w kontekście rozwoju marketingu postmodernistycznego [Badot, Cova, 2003; Brown i in. 2003]. Według Holbrooka i Schindlera [1991] nostalgia to pozytywne nastawienie lub korzystna postawa wobec ludzi, miejsc, produktów i marek, które były znane (popularne, modne i szeroko rozpowszechnione), w czasach młodości konsumenta. Pojęcie młodości jest tu jednak względne i w zależności od wieku konsumenta obejmuje wczesny wiek dorosłości, młodość, dzieciństwo, a nawet okres historyczny (przed urodzeniem). Z kolei Divard i Robert-Demontrond [1997] definiują nostalgię jako emocjonalną odpowiedź konsumenta na bodziec zewnętrzny lub wewnętrzny odwołujący się do wyidealizowanej przeszłości. Definicja ta podkreśla emocjonalną dominantę nostalgii i odnosi się do podziału Bakera i Kennedy [1994], odróżniających trzy kategorie nostalgii: nostalgię prawdziwą, nostalgię symulowaną oraz nostalgię zbiorową.

$\mathrm{W}$ artykule przyjmuje się, iż marka nostalgiczna, to marka kojarząca się z bliską lub dalszą, własną lub historyczną przeszłością. W oparciu o wybrane klasyfikacje zjawiska nostalgii wyróżnić można dwie podstawowe kategorie marek nostalgicznych:

- marki pokoleniowe, oparte na nostalgii prawdziwej (odnoszącej się do własnych, bezpośrednich i osobistych wspomnień), mającej charakter indywidualny lub zbiorowy,

- marki międzypokoleniowe, oparte na nostalgii prawdziwej (odnoszącej się do własnych, bezpośrednich i osobistych wspomnień) lub nostalgii symulowanej (odnoszącej się pośrednio do indywidualnych doświadczeń lub wspomnień innych osób, np. rodziców, dziadków, a także do zbiorowych doświadczeń lub wspomnień - tzw. nostalgia historyczna).

\section{Badania marketingowe w obszarze nostalgii}

Obserwując aktualne trendy zarządzania marketingowego, nie jest zaskakujący fakt, iż koncepcja nostalgii wzbudza zainteresowanie naukowców, którzy analizują to zjawisko $\mathrm{w}$ marketingu w różnych kontekstach badawczych. Problematyka wpływu nostalgii na postawy i zachowania konsumentów jest w konsekwencji obecnie poruszana w wiodących światowych periodykach (m.in. „Journal of Marketing Research”, „Journal of Marketing”, „Journal of Advertising Research” czy „Advances in Consumer Research"), uznanych przez środowisko naukowe.

Dotychczasowe zainteresowanie przedstawicieli ośrodków akademickich i badawczych skupia się przede wszystkim na analizie [Holbrook, Schindler 1991; Holbrook 1993; Holak, Havlena 1998; Baker, Kennedy 1994; Holak i in. 2008; Lacoeu- 
ilhe 2000; Kessous, Roux 2010; Stern 1992; Pascal i in. 2002; Muehling i in. 2014; Reisenwitz i in. 2004; Muehling, Pascal 2011; Rousseau, Venter 2000; Sierra, McQuitty 2007; Lambert-Pandraud, Laurent 2010; Merchant, Ford 2010; Chun-Chin Chen 2014]:

- wpływu nostalgii na zachowania konsumentów w kontekście popytu na produkty powiązane z przeszłością (Belk 1990; Holbrook i Schindler 1991; Holbrook 1991, 1993; Kleine i in. 1995; Lewis i Bridger 2000; Hedbergh i Singh 2001; Lowe 2002; Seidel 2003; Gruenewald 2003; Hein 2003; Geissler 2004; Loveland $i$ in. 2010),

- wpływu różnych kategorii nostalgii na postawy i zachowania konsumentów (Holak i Havlena 1992; Baker i Kennedy 1994; Divard 1997; Goudling 2001; Holbrook i Schindler 2003; Holak i in. 2008; Kiessling i in. 2012; Muehling 2013),

- wpływu nostalgii na postawy wobec marek (Lacoeuilhe 2000; Heilbrunn 2001; Kessous i Roux 2010),

- wykorzystania elementów nostalgii w reklamie (Stern 1992; Pascal i in. 2002; Perrusson 2003; Muehling i Sprott 2000; Reisenwitz i in. 2004; Marchegiani i Phau 2010; Muehling i Pascal 2011; Muehling 2013; Muehling i in. 2014),

- wpływu cech demograficznych na postawy nostalgiczne konsumentów (Holbrook i Schindler 1994; Rousseau i Venter 1999, 2000; Evans i in. 2010),

- wpływu nostalgii na zachowania konsumentów dla wybranych kategorii produktów (Rindfleisch i in. 2000; Holbrook i Schindler 2003; Sierra i McQuitty 2007; Chou i Lien 2010; Lambert-Pandraud i Laurent 2010),

- dostosowania metodyki badania nostalgii w zależności od różnic kulturowych (Borgis i Boulbry 2003),

- wpływu nostalgii na postawy charytatywne (Merchant i Ford 2010),

- wpływu nostalgii na wybór opakowania (Chun-Chin Chen 2014).

Wyniki badań prowadzonych w zagranicznych ośrodkach potwierdzają pozytywny wpływ nostalgii na postawy i zachowania konsumentów, zwłaszcza w obszarze komunikacji marketingowej.

W trakcie realizacji badań marketingowych dotyczących postaw i zachowań konsumentów wobec marek nostalgicznych zagraniczni badacze stosują istniejące lub autorskie techniki pomiarowe pozwalające na ocenę poszczególnych marek oraz dokonanie porównań lub stworzenie list rankingowych.

Jedną z częściej wykorzystywanych technik pomiaru jest pomiar poziomu kapitału marki według Aakera [1991], bazujący na ocenie świadomości marki, lojalności wobec marki, postrzeganej jakości marki oraz deklarowanej chęci zakupu produktów sygnowanych daną marką. Badanie opiera się na 13 pytaniach, które umożliwiają dokonanie porównania kapitału marki nostalgicznej i nienostalgicznej. Z kolei Hess [1995] dokonuje oceny postaw wobec marek w oparciu o pomiar zaufania do marki. Podobne podejście reprezentują Gurviez i Korchia [2002], którzy także proponują ocenę marek nostalgicznych w oparciu o pomiar poziomu zaufania do marki. 
Zaufanie to wyraża się poprzez wiarygodność marki, jej integralność oraz życzliwość. Lacoeuilhe [2000] dokonuje oceny postaw konsumentów wobec marek w oparciu o pomiar poziomu przywiązania do marki. Strazzieri [1994, za: Lacoeuilhe 2000] ocenia marki w oparciu o poziom zaangażowania konsumenta, a Richins [1994, za: Lacoeuilhe 2000], Fournier [1994, za: Lacoeuilhe 2000] i Klein i in. [1995 za: Lacoeuille 2000] w oparciu o zbieżność wizerunków marki i konsumenta. Richins [1994, za: Lacoeuilhe 2000] oraz Klein i in. [1995, za: Lacoeuilhe 2000] wskazali także na konieczność wyróżnienia pytań dotyczących stricte związków nostalgicznych z marką. Audrain i Evrard [2001] podczas oceny postaw wobec marek proponują wykorzystać pomiar satysfakcji z użytkowania marki, a Cristau [2003] pomiar poziomu prozelityzmu, wyrażającego się chęcią rozmowy o marce czy dzielenia się doświadczeniami związanymi z marką (tab.1).

Tabela 1. Przykładowe elementy marek podlegające ocenie

\begin{tabular}{|l|l|}
\hline \multicolumn{1}{|c|}{ Autor, rok } & \multicolumn{1}{c|}{ Elementy podlegające ocenie } \\
\hline Aaker, 1991 & kapitał marki \\
\hline Lacoeuilhe, 2000 & przywiązanie do marki \\
\hline Hess, 1995 & zaufanie do marki \\
\hline Gurviez i Korchia, 2002 & zaufanie do marki \\
\hline Strazzieri, 1994 & zaangażowanie \\
\hline Richins, 1994 & zbieżność wizerunków marki i konsumenta \\
\hline Fournier, 1994 & zbieżność wizerunków marki i konsumenta \\
\hline Kleine i in., 1995 & zbieżność wizerunków marki i konsumenta \\
\hline Richins, 1994 & związki nostalgiczne \\
\hline Kleine i in., 1995 & związki nostalgiczne \\
\hline Audrain i Evrard, 2001 & satysfakcja \\
\hline Cristau, 2003 & prozelityzm \\
\hline
\end{tabular}

Źródło: opracowanie własne.

Tabela 2. Pytania dotyczące cech marek nostalgicznych według Pascala i in.

\begin{tabular}{|l|}
\hline Marka przypomina mi o przeszłości \\
\hline Marka pomaga przywołać miłe wspomnienia \\
\hline Marka sprawia, że czuję się nostalgicznie \\
\hline Marka przywołuje wspomnienia z minionych lat \\
\hline Marka sprawia, że myślę o czasach młodości \\
\hline Marka przywołuje zamglone wspomnienia \\
\hline Marka jest przyjemnym przypomnieniem przeszłości \\
\hline Marka przywraca wspomnienia z dobrych czasów z przeszłości \\
\hline Marka przypomina mi stare dobre czasy \\
\hline Marka przypomina mi o dobrych latach w przeszłości \\
\hline
\end{tabular}

Źródło: [Pascal, Sprott, Muehling 2002, s. 39-49]. 
Pascal, Sprott i Muehling [2002] stworzyli kwestionariusz pozwalający na ocenę 10 elementów związanych z nostalgicznymi postawami konsumentów wobec marek. Poszczególne elementy oceniane są zwykle z wykorzystaniem skali Likerta (tab. 2).

Techniki pomiaru zaproponowane w obszarze zarządzania marką nostalgiczną mogą być wykorzystywane podczas dalszych badań.

\section{Postawy nostalgiczne młodych konsumentów z Francji i Polski wobec marek - przykładowe wyniki badań pilotażowych}

Badania mające na celu identyfikację, ocenę i porównanie postaw nostalgicznych młodych konsumentów (18-24 lata) wobec marek miały charakter międzynarodowy. Badania przeprowadzono na grupie 400 młodych konsumentów w pierwszym i drugim kwartale 2015 roku we Francji i w Polsce. Dobór respondentów był celowy. Wykorzystana została metoda pośredniego gromadzenia informacji z wykorzystaniem techniki ankiety. W ramach realizacji badań dokonano porównania nostalgicznych postaw konsumentów wobec badanych marek retro oraz chęci ich zakupu (w oparciu o istniejące techniki pomiarowe stworzone do oceny marek). W kwestionariuszu zastosowano 5-stopniową skalę Likerta. Badanie miało charakter opisowy w postaci badania przekrojowego. Respondenci nie byli informowani o celu badania. W trakcie realizacji badania wykorzystano marki nostalgiczne wskazane przez ekspertów oraz przez samych konsumentów (w ramach badań wstępnych).

Poniżej przedstawiono przykładowe wyniki badań. Należy zaznaczyć, że ze względu na ograniczenia redakcyjne zaprezentowano jedynie wybrane aspekty podjętej problematyki, gdyż nie było możliwości szczegółowego i kompleksowego omówienia wyników badań.

Ocena postaw nostalgicznych młodych konsumentów wobec marek dokonana została m.in. w oparciu o model kapitału marki Aakera oraz technikę pomiarową NOST (Evoked Nostalgia Scale) Pascala i in.

Analiza wyników badań o charakterze ilościowym w obszarze pomiaru kapitału marek nostalgicznych wskazuje, że młodzi konsumenci z Francji i Polski wykazują wysoki poziom świadomości marek nostalgicznych, zarówno pokoleniowych, jak i międzypokoleniowych. Analizowane marki - zarówno pokoleniowe, jak i międzypokoleniowe - kojarzą się młodym konsumentom z przeszłością własną bądź symboliczną. W przypadku marek nostalgicznych pokoleniowych skojarzenia obejmują wydarzenia i osoby z dzieciństwa, postacie z bajek oraz uczucia o pozytywnym charakterze. W przypadku marek nostalgicznych międzypokoleniowych są to najczęściej postacie i wydarzenia historyczne. Dobrze oceniono postrzeganą jakość badanych marek, przy czym ocena respondentów z Polski była wyższa aniżeli respondentów francuskich. Najniżej oceniono lojalność wobec marek nostalgicznych. Pozytywne skojarzenia i wysoka świadomość marek nie przekładają się na 
lojalność konsumentów, zwłaszcza w przypadku marek międzypokoleniowych. Podsumowując, ocena kapitału marek jest dobra w przypadku marek nostalgicznych pokoleniowych oraz neutralna w pozostałych przypadkach.

Zarówno w przypadku badanych marek nostalgicznych międzypokoleniowych, jak i pokoleniowych dostrzeżono postawy nostalgiczne młodych konsumentów. Dotyczy to zarówno marek funkcjonujących na rynku, jak i marek wycofanych. Przykłady przedstawiono na rysunkach 1-3. Nie wykazano przy tym korelacji pomiędzy oceną poziomu kapitału marki a poziomem postaw nostalgicznych.

Marka jako przypomnienie przeszłości

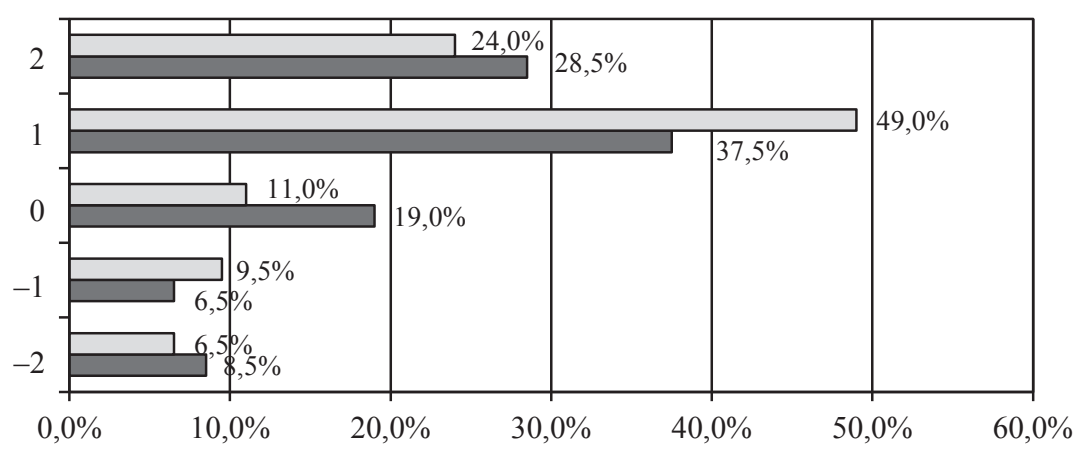

$\square$ Konsumenci z Polski $\quad \square$ Konsumenci z Francji

Rys. 1. Marka Coca-Cola - ocena postaw nostalgicznych

Źródło: opracowanie własne na podstawie wyników badań.

Marka jako przypomnienie przeszłości

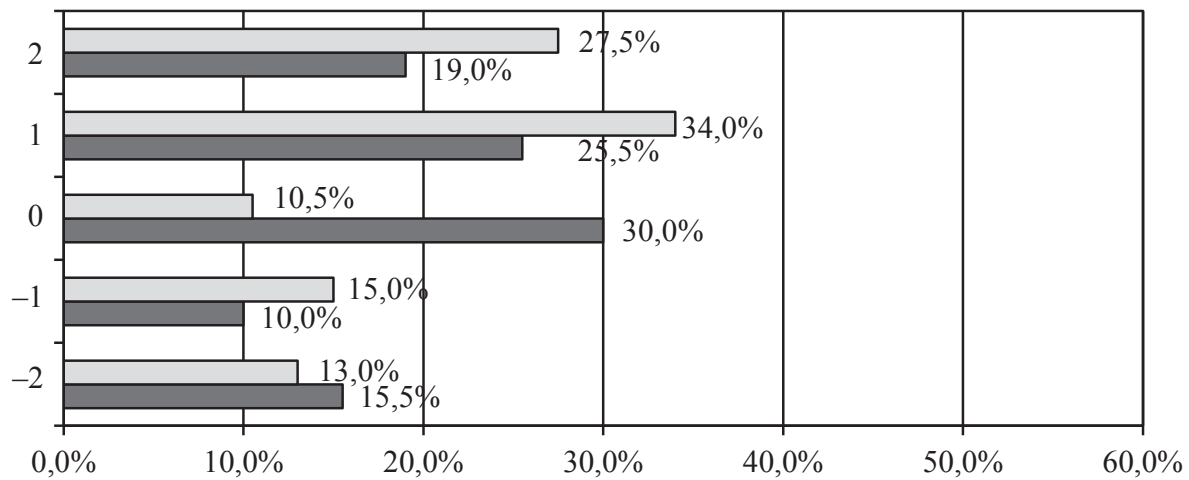

口Konsumenci z Polski $\quad \square$ Konsumenci z Francji

Rys. 2. Marki Wedel i La mère Poulard - ocena postaw nostalgicznych

Źródło: opracowanie własne na podstawie wyników badań. 
Marka jako przypomnienie przeszłości

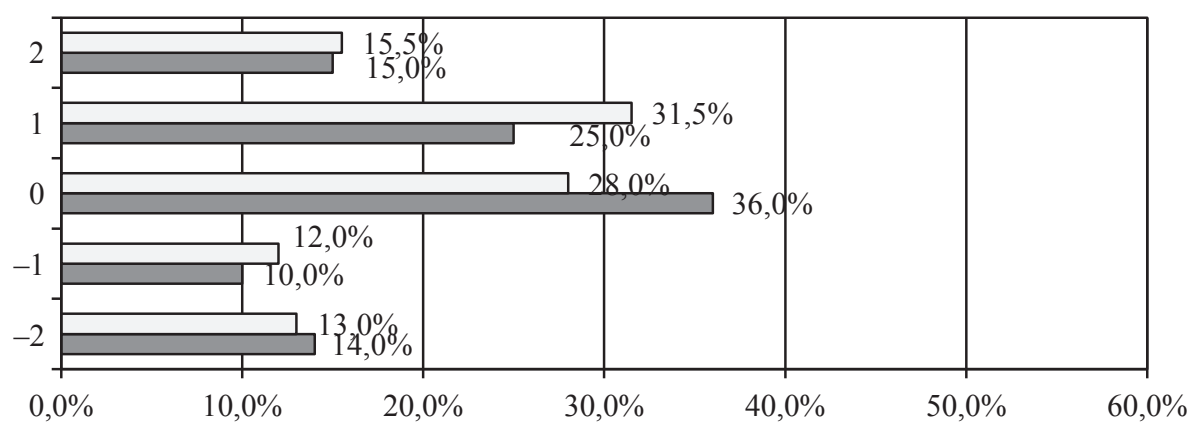

口Konsumenci z Polski $\quad \square$ Konsumenci z Francji

Rys. 3. Marka Kodak - ocena postaw nostalgicznych

Źródło: opracowanie własne na podstawie wyników badań.

W przypadku marek Coca-Cola oraz Wedel (Polska) i La mère Poulard (Francja), młodzi konsumenci w większości przypadków deklarują, iż marki te przypominają o przeszłości oraz wywołują miłe wspomnienia związane z dzieciństwem (tj. przeszłością indywidualną). W przypadku marki Kodak niemal połowa polskich i $40 \%$ francuskich respondentów potwierdziło nostalgiczne uczucia wobec marki, mimo jej braku na rynku.

Tabela 3. Cechy marki Coca-Cola w kontekście oceny marki nostalgicznej według Pascala i in.

\begin{tabular}{|l|l|c|l|}
\hline \multicolumn{1}{|c|}{ Cecha } & $\begin{array}{c}\text { Ocena } \\
\text { negatywna } \\
(-2 /-1)\end{array}$ & $\begin{array}{c}\text { Ocena } \\
\text { neutralna } \\
(0)\end{array}$ & $\begin{array}{c}\text { Ocena } \\
\text { pozytywna } \\
(1 \text { i } 2)\end{array}$ \\
\hline Marka przypomina mi o przeszłości & $15,5 \%$ & $15 \%$ & $69,5 \%$ \\
\hline Marka pomaga przywołać miłe wspomnienia & $20 \%$ & $15 \%$ & $65 \%$ \\
\hline Marka sprawia, że czuję się nostalgicznie & $47 \%$ & $21 \%$ & $32 \%$ \\
\hline Marka przywołuje wspomnienia z minionych lat & $18,5 \%$ & $14 \%$ & $67,5 \%$ \\
\hline Marka sprawia, że myślę o czasach młodości & $20 \%$ & $18 \%$ & $62 \%$ \\
\hline Marka przywołuje zamglone wspomnienia & $38 \%$ & $21 \%$ & $41 \%$ \\
\hline Marka jest przyjemnym przypomnieniem przeszłości & $16,5 \%$ & $15 \%$ & $68,5 \%$ \\
\hline Marka przywraca wspomnienia z dobrych czasów z przeszłości & $25 \%$ & $19 \%$ & $56 \%$ \\
\hline Marka przypomina mi stare dobre czasy & $32 \%$ & $12 \%$ & $56 \%$ \\
\hline Marka przypomina mi o dobrych latach w przeszłości & $21,5 \%$ & $11 \%$ & $67,5 \%$ \\
\hline
\end{tabular}

Źródło: opracowanie własne na podstawie wyników badań przygotowanych w oparciu o [Pascal, Sprott, Muehling 2002, s. 39-49]. 
W przypadku marki Coca-Cola ponad 50\% konsumentów z Polski i Francji zadeklarowało, iż marka przywołuje miłe wspomnienia z minionych lat, sprawia, że myślą o przeszłości, jest przyjemnym przypomnieniem przeszłości, przywraca wspomnienia z dobrych czasów z przeszłości oraz przypomina o nich. Natomiast tylko $32 \%$ respondentów zadeklarowało, iż marka sprawia, że czują się nostalgicznie, a $41 \%$, że przywołuje zamglone wspomnienia (tab. 3 ).

\section{Podsumowanie}

W warunkach współczesnego rynku marka stała się kluczowym elementem marketingu, a strategii marki coraz częściej podporządkowuje się inne narzędzia marketingowe. Obserwacje trendów rynkowych dowodzą, iż rozwój marek jest nieuchronny. Wymóg bycia konkurencyjnym zmusza przedsiębiorstwa do podejmowania nietradycyjnych działań w zakresie marketingu, a tym samym dostosowania się do preferencji konsumentów i zachowań konkurentów. W obliczu przemian dokonujących się $\mathrm{w}$ otoczeniu współczesnych przedsiębiorstw marka jest punktem odniesienia umożliwiającym konsumentowi ocenę zarówno materialnych cech produktu, jak i fundamentalnych niematerialnych wartości związanych z marką. Jednocześnie obserwujemy wyraźną tendencję podejmowania działań marketingowych odwołujących się do emocji, przeżyć i wspomnień konsumentów. Fundamentem więzi między konsumentem a marką może być nostalgia, będąca pozytywnym nastawieniem wobec marek, które są w sposób bezpośredni lub pośredni związane z przeszłością.

\section{Literatura}

Aaker D.A., 1991, Managing Brand Equity, Editions Free Press, New York.

Audrain A.-F., Evrard Y., 2001, Précision et discriminance du concept de satisfaction des consommateurs, Actes du 17ème Congrès International de l'Association Française du Marketing, Deauville, CD-ROM.

Badot O., Cova B., 2003, Néo-Marketing, 10 ans après, Revue Française du marketing, vol. 195, s. 79-94.

Baker S.M., Kennedy P.F., 1994, Death by nostalgia: A diagnosis of context - specific cases, Advances in Consumer Research, vol. 21, s. 169-174.

Brown S., Kozinets R.V., Sherry Jr. J.F., 2003, Teaching old brands new tricks: retro branding and the revival of brand meaning, Journal of Marketing, vol. 67 (July), s. 19-33.

Chun-Chih Chen J., 2014, The impact of nostalgic emotions on consumer satisfaction with packaging design, Journal of Business and Retail Management Research (JBRMR), vol. 8, issue 2, s. 71-79.

Cristau C., 2003, Définition, mesure et modélisation de l'attachement à une marque comme la conjonction de deux dimensions distinctes et concomitantes: la dépendance et l'amitié vis-à-vis de la marque, Congrès International „Les tendances du marketing”, Venise.

Davis F., 1979, Yearning for Yesterday: A Sociology of Nostalgia, The Free Press, New York.

Divard R., Robert-Demontrond P., 1997, La nostalgie: un thème récent dans la recherche marketing, Recherche et Applications en Marketing, vol. 12 (4), s. 41-62. 
Gurviez P., Korchia M., 2002, Proposition d'une échelle de mesure multidimensionnelle de la confiance dans la marque, Recherche et Applications en Marketing, vol. 17(3), s. 41-61.

Hess J., 1995, Construction and Assessment of a Scale to Measure Consumer Trust, AMA Educators' Conference, Enhancing Knowledge Development in Marketing, vol. 6, s. 20-25.

Holak S.L., Havlena W.L., 1998, Feelings, Fantasies, and Memories: an Examination of the Emotional Components of Nostalgia, Journal of Business Research, vol. 42, s. 217-226.

Holak S., Matveev A.V., Havlena W.J., 2008, Nostalgia in post-socialist Russia: Exploring applications to advertising strategy, Journal of Business Research, vol. 61(1), s. 172-178.

Holbrook M.B., 1993, Nostalgia and consumption preferences: some emerging patterns of consumer tastes, Journal of Consumer Research, vol. 20(2), s. 245-256.

Holbrook M.B., Schindler R.M., 1991, Echoes of the Dear Departed Past: some work in progress on nostalgia, Advances in Consumer Research, vol. 18, s. 330-333.

Kessous A., Roux E., 2008, Nostalgia - a connection to the past: a semiotic analysis, Qualitative Market Research: An International Journal, vol. 11, no. 2, s. 192-212.

Kessous A., Roux E., 2010, Les marques perçues comme «nostalgiques»: conséquences sur les attitudes et les relations des consommateurs à la marque, Recherche et Applications en marketing, vol. 25(3), s. 29-56.

Lacoeuilhe J., 2000, L'attachement à la marque: proposition d'une échelle de mesure, Recherche et Applications en Marketing, vol. 15, $\mathrm{n}^{\circ} 4$, s. 61-77.

Lambert-Pandraud D.R., Laurent G., 2010, Why do older consumers buy older brands: the role of attachment and declining innovativeness, Journal of Marketing, vol. 74 (5), s. 104-121.

Loveland K.E., Smeesters D., Mandel N., 2010, Still preoccupied with 1995: the need to belong and preference for nostalgic products, Journal of Consumer Research, vol. 37 (3), s. 393-408.

Merchant A., Ford J.B., 2008, Nostalgia and giving to charity: a conceptual framework for discussion and research, International Journal of Nonprofit and Voluntary Sector Marketing, vol. 13 (1), s. 13-30.

Muehling D.D., Pascal V.J., 2011, An empirical investigation of the differential effects of personal, historical, and non-nostalgic advertising on consumer responses, Journal of Advertising, vol. 40 (2), s. 107-122.

Muehling D.D., Sprott D.E., 2000, The power of reflection: an empirical examination of nostalgia advertising effects, Journal of Advertising, vol. 33 (3), s. 25-35.

Muehling D.D., Sprott D.E., Sultan A., 2014, Exploring the boundaries of nostalgic advertising effects: a consideration of childhood brand exposure and attachment on consumers' responses to nostalgia-themed advertisements, Journal of Advertising, vol. 43 (1), s.73-84.

Pascal V.J., Sprott D.E., Muehling D.D., 2002, The influence of evoked nostalgia on consumers 'responses to advertising: and exploratory study, Journal of Current Issues and Research in Advertising, vol. 24 , no.1, s. 39-49.

Reisenwitz T.H., Iyer R., Cutler B., 2004, Nostalgia advertising and the influence of nostalgia proneness, Marketing Management Journal, vol.14 (2), s. 55-66.

Rousseau G.G., Venter D.J.L., 2000, The relationship between nostalgia and consumer preference: replication and extension, Journal of Industrial Psychology, vol. 26 (2), s. 32-36.

Sierra J.J., McQuitty S., 2007, Attitudes and emotions as determinants of nostalgia purchases: an application of social identity theory, Journal of Marketing Theory and Practice, vol.15 (2), s. 99-112.

Stern B.B., 1992, Historical and personal nostalgia in advertising text: the fin de siecle effect, Journal of Advertising, vol. 21(4), s.11-22. 